\title{
Habitar Íntimo: A Poesia de Eduardo Dall'alba
}

\author{
Vera Lúcia de Olineira*
}

RESUMO: Eduardo Dall'Alba (1963-2013) publicou mais de dez livros, incluindo ensaios e poesia, e recebeu diversos prêmios. Vindo de família de imigrantes de origem veneta, estabeleceu-se no Rio Grande do Sul no final do século XIX. Profundo conhecedor da literatura italiana e estudioso de Dante, conseguiu fundir as duas culturas e identidades, a brasileira e a italiana. Proponho-me a evidenciar, aqui, como a poesia do autor recupera a vivência recalcada e silenciada dos milhares de imigrantes italianos no sul do Brasil, contemplando suas dores, a frustração por terem deixado a própria terra, a nostalgia e a obsessão pela autossuficiência econômica que se obtinha pelo trabalho incessante de todos os membros da família, o dialeto ou os dialetos, vistos como elemento aglutinador das primeiras comunidades.

PALAVRAS-CHAVE: Eduardo Dall'Alba; poesia brasileira; imigração italiana no Brasil.

ABSTRACT: Eduardo Dall'Alba (1963-2013) ha pubblicato oltre dieci libri,

\footnotetext{
* Università degli Studi di Perugia
} 
tra saggi e poesia, ed ha ricevuto diversi premi. Appartiene ad una famiglia di emigranti veneti stabilitosi del Rio Grande do Sul alla fine dell'Ottocento. È un profondo conoscitore della letteratura italiana, studioso di Dante, Eduardo è riuscito a fondere le due culture e identità, quella brasiliana a quella italiana. Qui desidero enfatizzare come la poesia di quest'autore recupera il vissuto rimosso e senza voce di migliaia di italiani emigrati al sud del Brasile, con il loro dolore e la loro frustrazione per aver abbandonato la propria terra, la nostalgia e l'ossessione di autosufficienza economica che si otteneva tramite il lavoro incessante di tutti $i$ componenti della famiglia, il cui dialetto - o dialetti - erano visti quale elemento agglutinante delle prime comunità .

PAROLE CHIAVE: Eduardo Dall'Alba; poesia brasiliana; immigrazione italiana in Brasile.

ABSTRACT: Eduardo Dall'Alba (1963-2013) has published more than ten books, including essay and poetry, and has received numerous awards. His family of Venetian origin of immigrants settled in Rio Grande do Sul in the late 1800s. With a deep knowledge of Italian literature and being a scholar of Dante, the writer was able to fuse the two cultures and identities, Brazilian and Italian. I highlight here how his poetry can recover the repressed and silenced experience of thousands of Italian immigrants in southern Brazil, with their pain, frustration for leaving their own land, nostalgia, obsession with economic independence obtained hard work of all the family members, the dialect or dialects considered the glue of the first communities.

KEYWORDS: Eduardo Dall'Alba; Brazilian poetry; Italian immigration in Brazil. 
"o mistério do ser inacabado de ser o mesmo sendo diferente ser impreciso, mas reinventado sob o plano do espaço permanente."

Eduardo Dall' Alba

duardo Dall' Alba, poeta, professor e pesquisador, nasceu em Caxias do Sul em 4 de dezembro de 1963, e faleceu recentemente, em 24 de dezembro de 2013. Publicou mais de dez livros, incluindo ensaios e poesia, e recebeu diversos prêmios pela sua produção, dentre os quais o Prêmio Açorianos de Literatura, em 1998. A família, de origem italiana, imigrada da localidade de Schio, no Vêneto, no final do século XIX, estabeleceu-se inicialmente em Flores da Cunha e depois em Caxias do Sul, no Rio Grande do Sul.

Intelectual fino e sutil, profundo conhecedor da literatura italiana e estudioso de Dante, Eduardo conseguiu, em sua obra fundir as duas culturas e as duas identidades, a brasileira e a italiana. A Itália, contudo, mais do que um lugar físico, é um espaço da alma, um espaço imaginário, filtrado pela narração dos idosos da família que, da Itália, conservavam alguma 
memória. Em casa, a língua materna era o dialeto de Schio, língua dos sentimentos mais íntimos, das decisões importantes e, às vezes, utilizada quase como um código secreto de grupo, sobretudo à presença de pessoas estranhas ou externas, por vezes da própria família, como noras e genros. Afirma Eduardo: "O dialeto foi minha primeira língua e é a língua do sentimento, do coração, do amor" (Comunicação pessoal, 19/01/2013) O idioma italiano, ao contrário, foi adquirido mais tarde, já na universidade.

Sobre a Itália, conhecida sobretudo pelos livros e filmes, ele afirma:

Amo ouvir o dialeto da Sicília. Amo o Poderoso chefão, filme que me faz chorar só de ouvir um personagem cantando em violão uma música que meu avô cantava quando eu era menino, no porão da casa dele, enquanto serrava lenha; a música é aquela, que é um dos temas da trilogia de Francis Ford Coppola. Amo aquelas casas antigas das vilas daquela parte da Itália, me sinto parte daquilo ali, pedra, deserto, areia, frio, frieza, poder, máfia, morte, poder e também amo um filme em especial, aliás, dois, que são emblemáticos porque são a cara de nossa família: Padre padrone [dos irmãos Taviani] em que há uma cena em que o velho afoga o rádio-galena do filho na água, cena que eu vi igual muito antes de ver o filme, e ainda aquele outro que amo porque penso que sou exatamente como aquele homem, o da Árvore dos tamancos [de Ermanno Olmi], filme de imigrantes pobres que vêm para o sul.” (Comunicação pessoal, 19/01/2013)

É intrínseco à poesia de Eduardo o elemento evocativo, ligado ao mundo rural do sul do Brasil, onde o autor cresceu e viveu as primeiras experiências e descobertas, no seio de uma comunidade de imigrantes ainda profundamente ligada ao país de origem, o qual deixaram por necessidade. Se para essa comunidade a Itália é o universo da memória, idealizado porque longínquo e inalcançável para quem era pobre, para Eduardo há sempre duas Itálias, que correspondem a dois espaços não coincidentes e, por vezes, antitéticos.

A primeira é a pátria dos grandes poetas, intelectuais, artistas, compositores e cineastas amados e admirados, capazes de plasmarem a dureza da vida em harmonia e beleza estética. Daí a admiração por Dante, para ele o poeta máximo; daí o amor pelo cinema italiano, que o comovia profundamente. O cordão umbilical que ele mantinha com esse espaço intacto e quase mítico é o mesmo que o ligava à poesia, sempre vista como sinônimo de extrema liberdade. 
A outra Itália era a da lida concreta e dura na colônia, uma Itália menor que os imigrantes tentaram preservar e reconstruir a todo custo no sul do Brasil, com o ritmo da vida ligada ao da natureza e de suas estações, atravessado pela hierarquia e rígidos valores patriarcais e católicos. Se a primeira Itália representou sempre o modelo utópico só alcançado pela poesia, a segunda era convocada e exorcizada obstinadamente em sua obra; se a primeira era a pátria da palavra e, em geral, da arte livre e libertadora, a segunda era a do emparedamento, do silêncio e dos conflitos geracionais que deixavam traumas profundos.

A poesia de Eduardo Dall'Alba recupera, assim, toda uma vivência recalcada e silenciada: a dos milhares de imigrantes, contemplando suas dores e a frustração de terem que deixar a própria terra, a nostalgia, a obsessão pela autossuficiência econômica obtida pelo trabalho incessante de todos os membros da família, a religiosidade por vezes sufocante, o dialeto (ou os dialetos), visto como elemento aglutinador das primeiras comunidades, o desprezo pela cultura letrada e pelo trabalho intelectual em geral, o apego ao passado e a resistência às transformações. Em tal sentido, pode-se referir a sua obra com a mesma definição que o autor usou em um artigo ainda inédito, onde caracteriza o que chama de "poesia do interdito", esclarecendo que "o interdito rompe a linguagem e faz do poema uma espécie de grito, uma forma de libertar a dor do não dito" ". Tal definição adere perfeitamente ao seu tipo de dicção lírica, à especificidade de sua busca por uma poesia capaz de inaugurar e abrir espaços inusitados. Nela, tudo pode e deve ser dito, tudo pode emergir, tudo deve ser meticulosamente recuperado e analisado.

Não há na poesia de Dall'Alba qualquer tentativa de leitura e interpretação da imigração italiana em termos heroicos, como às vezes ocorre em discursos oficiais em que o imigrante é apresentado como uma espécie de desbravador de territórios desabitados do nosso sul. A vida é real, a dor é viva, a terra é ávida de fadiga humana, e não há heróis, não há pompa ou retórica, apenas homens e mulheres lutando da melhor maneira possível para sobreviver.

Afirma Riobaldo, o angustiado personagem de Guimarães Rosa, em Grande sertão: veredas: "Ah, tem uma repetição, que sempre outras vezes em minha vida acontece. Eu atravesso as coisas - e no meio da travessia não vejo! - só estava era entretido na ideia dos lugares de saída e de chegada" (GUIMARÃES ROSA, 1978, p. 30). Como Riobaldo, o poeta Eduardo Dall'Alba retorna para inventariar e para entender o vivido, para iluminar uma travessia feita pelo menino e adolescente que não tinha ainda, talvez, as palavras idôneas para aclarar cada momento e ângulo do percurso feito.

1 Refiro-me aqui a texto ainda inédito, enviado-me pelo poeta em comunicação pessoal. 
"Inventário" é, assim, a palavra-chave nessa poética despojada: "Cravo os olhos no inventário de bens e coisas deste quarto/ desta sala, deste sótão, que dá para o corredor./ Esta casa viaja em mim." (DALL'ALBA, 2006, p. 135). "Inventário" é também o título de um poema emblemático, onde há uma enumeração aparentemente caótica de objetos:

1 pistola de dois canos

em cabo de madrepérola

1 gaita ponto

1 par de tamancos

1 tamanco sozinho

10 navalhas de barbear suecas

1 aparelho de cortar cabelo

4 canivetes (Ibid., p. 169)

O poema não é, porém, apenas o inventário de coisas ou de objetos de uma casa ou de uma existência; é também o resgate de momentos, atos, sentimentos, emoções, pensamentos, ímpetos, cacos de uma louça que é a vida mesma, a qual, depois de rota, não pode mais ser recomposta senão pela palavra poética. Em “O medo 1970”, no delicado rendilhado do seu lirismo, encontramos, recompostos, os fragmentos da fina porcelana da mãe e os do seu coração ferido, que se juntam de novo, traçando e trançando uma forma nova, que, sem esconder as feridas, transfiguram-nas e transcendem o individual para alcançar o universal das experiências de perda e de abandono:

Sob as pranchas do soalho, ouço tudo, toda coisa dita aos gritos na cozinha:

eram duas dúzias de louça que voavam pelo chão, eram os sonhos de nossa mãe indo para o beleléu era a vida difícil [...] 
Ouço as botas de meu pai

descendo a escada de fora

vai viajar, ver os amigos

desabafar com o padre

que pouco entende da família!?

Saiu, e respiramos aliviados, contristados,

enquanto catamos os cacos de porcelana

e os cacos do coração de nossa mãe

espalhados na cozinha (Ibid., p. 136).

O poeta retrocede no tempo, retorna meticuloso ao passado com o instrumento de inquirição mais aguçado que existe, a poesia, revivendo e, sobretudo, recuperando e dando voz ao que estava silenciado. Nessa poesia catártica, emergem os personagens pobres, os seres desprovidos de aura, valor e função em uma sociedade competitiva e endurecida pelas necessidades elementares; emergem as humilhações de cada dia, o filho do colono pobre que tem que ir à missa com a calça de brim remendada, os casebres de pedra gelados no inverno, os porões tristes, onde as famílias empalhavam o vime horas a fio e as ofensas e angústias engolidas com as lágrimas.

É notável a presença na poesia de Dall'Alba do sintagma "pobre" declinado em todas as suas acepções, como "magro", "simples", "pouco", "batido", "cansado", "torto", "calado". Em "Poemas da colônia", texto articulado em várias partes, o autor reproduz vozes e falas desse mundo que o imigrante encontrou no Brasil, dialogando com outro grande poeta, quase nume tutelar para ele, João Cabral de Melo Neto, do livro Morte e vida Severina: "Vocês aqui não são nada mera e vasta colonada/ nas terras de outro patrão. E não lhes darão sementes/ e não lhes darão remédios, enxadas não lhes darão.” (Ibid., p. 171).

O eu lírico define sua poesia como "pobre", poesia do sem rumor e do sem valor, poesia do ser e do tempo que não chamam a atenção de ninguém. A tal propósito, ele adverte no poema “Aqui não há alquimias" que não se busque o artificioso ou o retórico em suas palavras, pois elas são claras, precisas e exatas, sem adornos ou floreios:

Este é filho de colono não de literato mas o que aprendeu com o pai 
cabe em muitos livros.

Aqui a forma simples do poeta

guarda a beleza da matéria.

Não, não há alquimias aqui

pedra ainda é pedra

angústia noturna é ainda angústia

e chumbo é chumbo:

o pouco é simples

dá, porém, para entender o mundo (Ibid., p. 89).

É tão bem evidenciada, na obra, a faina cotidiana dos imigrantes italianos, que a poesia de Dall'Alba acaba sendo, também, um documento precioso do ponto de vista sociológico e antropológico, pela minúcia de particulares e pela qualidade imagética do texto, que permite amiúde ao leitor seguir os vários momentos e atividades, sobretudo coletivas. E tantas eram nesse mundo as crianças, pois se partia do pressuposto que cada filho fosse um braço a mais para o trabalho, quer na lavoura, quer em outros ofícios necessários à sobrevivência familiar:

"Há que chegar rápido, entregar a uva

pegar a farinha no moinho,

saldar a dívida, comprar tecidos

e ferramentas no baratilho da cidade

é preciso entregar logo chegar logo

logo é preciso chegar,

amanhã é outro dia

- o dia é curto.” (DALL'ALBA, 2006, p. 137)

Esse obsessivo escavar no vivido, essa recuperação dos momentos da infância na colônia onde sobressai a figura autoritária do pai e, em contrapartida, a da mãe, que acalenta e cura os males físicos e psicológicos da família -, nunca é idealização de um mundo perdido. O retorno é feito, como se disse, pela palavra e com a palavra, que resgata o que restou desse vivido na memória e nos objetos e documentos herdados dos antepassados. Tudo é minuciosamente revisitado, tudo deve ser entendido, pois a viagem a ritroso tem um objetivo específico, como 
vimos: resgatar as vozes, as palavras não proferidas, os gritos mudos de uma humanidade da qual o eu lírico se sente e é parte integrante. É eloquente a recorrência nessa poesia de dois sintagmas antitéticos, postos em correlação: "grito mudo". Leia-se, de fato essa declaração de poética: "A minha poesia erra entre/ a cova, o estorvo e a erva./ Toda é um grito mudo." (Ibid., p. 272); "Canto, canto, canto, canto, o meu cantar é meu grito" (Ibid., p. 26).

É necessário ter em mente, porém, que não se trata de um registro estritamente cronológico do tempo passado, ao contrário: para o poeta, conta o tempo interior e dilatado da consciência, que não coincide com o do relógio; contam as horas lentas de trabalho, de estudo e de vida de um menino e de um adolescente extraordinariamente sensível, que passou pelo mundo "espiando, enxergando, olhando" (Ibid., p. 90).

A poesia é a sua lavoura, as palavras são os seus bens intangíveis, que também requerem lavra, paciência, preparação e empenho. Note-se que, em muitos poemas, o eu lírico é plural, um "nós" coletivo e solidário que congrega, além da voz do poeta, todas as vozes que recolhe e incorpora em seu canto: "Nós somos de algum lugar/ mas nem sabemos de onde" (Ibid., p. 293); “- Nós aqui não somos nada, longe aqui da pátria amada/ cabe a nós plantar a vida que na terra pedregosa/ foi a sorte repartida nós aqui não somos nada” Ibid., p. 171).

É viva nessa poética a lição de Drummond, autor tão amado e estudado por Eduardo Dall'Alba, o Drummond lírico e ao mesmo tempo anti-lírico que recomenda aos seus pares: "Não faças poesia com o corpo, [...]/ Não me reveles teus sentimentos, [...]/ O que pensas e sentes, isso ainda não é poesia.” (DRUMMOND DE ANDRADE, 1974, p. 76). Dall'Alba não é, de fato, um poeta confessional que se derrama na página, embora nunca se distancie completamente daquele núcleo vital que moldou seus primeiros anos. Afirma: "Espasmo e ato contínuo e opresso/ Escrevo o fato não me confesso.” (DALL'ALBA, 2006, p. 258).

A poesia, para ele, é sempre encontro², salvação, sonho, utopia e, por fim, arma:

\author{
A palavra é minha arma \\ com ela me defendo dos males do mundo, \\ do comum vício ácido da crítica, \\ do mau verso do mau livro; \\ A palavra é minha arma \\ [...] \\ tudo que escavo é sentido;
}

2 A tal propósito, nos últimos meses de vida Eduardo se dedicou com paixão e afinco à concretização de um sonho longamente acalentado: o de reunir em uma antologia alguns dos autores com os quais tinha afinidades. Nasceu assim a antologia Palavra não é coisa que se diga, publicada pela Age Editora, Porto Alegre, 2013, que reúne oito poetas: Celso Gutfreind, Paulo Becker, Ricardo Silvestrin, Álvaro Santi, José Eduardo Degrazia, Jayme Paviani, Vera Lúcia de Oliveira e Eduardo Dall'Alba. 
disparo que se precisa
a todo entendimento
e não preciso de gangue
nem de exércitos preciso
minha palavra dá conta,
mar diminuto e conciso,
da trajetória da bala;
carece de explicação
quanto mais explique a lavra
a palavra é minha arma
a arma é minha palavra (Ibid., p.91).

Se a poesia é, como vimos, o inventário de uma vida nos seus vários momentos, sobretudo os dolorosos, a lírica de Dall'Alba é, paradoxalmente, leve e delicada. A figura que para ele representa o mais puro e perfeito modelo de arte é o da bailarina, que, com seus movimentos suaves e harmoniosos, cria a beleza, escondendo em seu vôo todas as horas passadas a preparálo e a torná-lo possível. Não é casual que o poeta dedica uma seção inteira do livro Os bens intangíveis à bailarina:

a bailarina percorre o vôo de ave em aviso:
a dor é grande no mundo precisa de lenitivo
a dor é grande no mundo mas tudo cala o segundo
onde se vê seu sorriso. Nem todo riso é alegre
é da tristeza que rimos de coração mais leve (Ibid., 2006, p. 126).

Ele quer uma poética livre, precisa e medida, mas também luminosa e leve, como a arte da dança; quer uma poesia que transfigure o vivido em música e beleza: "Assim como a dança, a prece outro rigor determina/ no rumor de sangue e sina e sobre si roda a fina/ e exigente disciplina" (Ibid., 2006, p. 125). E quer, nesse mesmo rigor, libertar o movimento reprimido sem ferir em demasia o leitor. O resultado é essa espécie de partitura, onde se cruzam e se conjugam a sensibilidade exacerbada, a intensidade do olhar, a paciência do labor minucioso, a coragem de ir até o fundo e o amor por toda criatura vivente. Sempre vale a pena a vida, mesmo nesse nosso lento morrer. 
$\mathrm{O}$ autor conscientemente assumiu, praticou e reivindicou uma poesia dos seres sem aura e sem glamour que o habitavam, dos animais humildes, dos momentos mínimos de um tempo vivido verticalmente, dos objetos descartáveis aos quais sempre fica enganchado algo do nosso ser, como bem se evidencia no intenso poema "Matéria de poesia":

Um caco de porcelana um prego

um anúncio de jornal

uma vassoura no canto

o sol poente ou nascente

a paisagem vista da janela

o corcel negro no campo aberto

o boi no campo

a solidão

a máquina de datilografia

a tv o som desligado o quarto

o livro fechado na estante

o poema que ninguém leu

o poema que não fiz

o relógio suizo do nono

a sala vazia o canto rouco

a pouca música deste poema

o cd do madredeus

a poesia dos outros poetas

becker santi silvestrin

a minha poesia como corpo

o corpo da mulher um corpo

qualquer corpo morto

qualquer corpo

[...]

uma casa abandonada

as tábuas desta casa desmanchada

a água da vertente que não cessa 


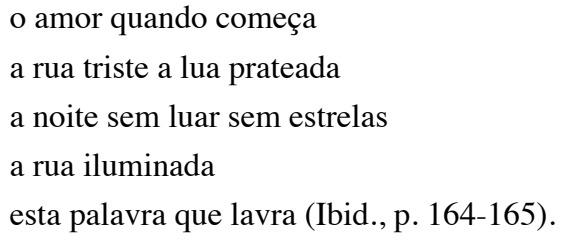

Foi necessária a poesia para que a palavra brotasse e fluísse de um rico reservatório de vivências. Dall'Alba nos deixou sua lavra mais rara, seu dom de percorrer a vida com uma voz original e participante e, por isso, capaz de compreender a dor alheia e de resgatá-la e transformá-la em formas luminosas. Dessa farta lavoura de versos tantos são os poemas antológicos, mas ficamos aqui com três dentre os mais tocantes, espécie declaração de amor e poética desse amigo que nos deixou tão precocemente:

\section{CÁLCULO MATEMÁTICO}

O economista se ri

do meu verso atravessado

ele não sabe - nunca saberá -

que a poesia é a música dos pobres

e das almas dos loucos, bêbados e desesperados

dos despojados do cânone (Ibid., p. 157).

\section{NOITE}

A noite é vasta, o tempo, um sonho.

Nisto se gasta o que suponho.

O amor é pouco, a vida, breve.

Neste momento não mais se escreve.

A noite cala a emoção tensa

Nisto se embala a minha crença.

Espasmo e ato contínuo e opresso. 
Escrevo o fato não me confesso (Ibid., p. 258).

AGORA

Agora caminhamos sobre as flores na relva agora não precisamos de flores não precisamos de abraços

não precisamos mais nada. Toda a alma é inusitada sem abraços e sem flores.

Agora não precisamos de amores a vida tem-se tornado amarga.

E mais limpa e mais larga, não precisamos de tempo

o vento nos cortou ao meio, entre o esquerdo e o direito

só, espia a um olho o seio, chove muito em Aldebarã não aparece nenhuma estrela.

O mais é mera paisagem, ao anoitecer do rio dos olhos, mera imagem (Ibid., p. 302).

\section{Referências bibliográficas}

DALL'ALBA, E. Os bens intangíveis: reunião 1988-2006. Caxias do Sul: Editora da Universidade de Caxias do Sul, 2006.

Vozes da poesia contemporânea. A dicção de Vera Lúcia de Oliveira e a poesia do interdito. Texto inédito.

DRUMMOND, C. Reunião - 10 livros de poesia. Rio de Janeiro: José Olympio Editora, 1974.

GUIMARÃES ROSA, J. Grande sertão:veredas. Rio de Janeiro: José Olympio Editora, 1978. 